Original Research Article

\title{
The effect of a polyherbal oral formulation in the management of essential hypertension: an open label, pilot clinical study
}

\author{
Rohit Sane ${ }^{1}$, Suhas Dawkhar ${ }^{2}$, Pranit Ambulkar ${ }^{1}$, Rahul Mandole ${ }^{1 *}$
}

\begin{abstract}
${ }^{1}$ Department of Research and Development, ${ }^{2}$ Department of Patient Engagement, Madhavbaug Cardiac Care Clinics and Hospitals. Mumbai, Maharashtra, India
\end{abstract}

Received: 16 April 2018 Accepted: 22 May 2018

\section{*Correspondence to:}

Dr. Rahul Mandole,

Email: cromilagro@gmail.com

Copyright: () the author(s), publisher and licensee Medip Academy. This is an openaccess article distributed under the terms of the Creative Commons Attribution NonCommercial License, which permits unrestricted noncommercial use, distribution, and reproduction in any medium, provided the original work is properly cited.

\begin{abstract}
Background: Effective control of blood pressure in patients with hypertension decreases cardiovascular mortality. However, many hypertensives are unresponsive to standard antihypertensive treatment. Research has found antihypertensive potential in the Ayurvedic drugs Brahmi (Bacopa monnieri) and Shunthi (Zingiber officinale). Hence, a pilot study was conducted to evaluate the efficacy and safety of Capsule Artyl (the oral formulation of Brahmi and Shunthi) as a treatment option in hypertensive subjects.

Methods: There were 30 hypertensive subjects attending out-patient departments of clinics in Maharashtra, India were enrolled in this four-week, open label, single arm study. All subjects received capsule Artyl (500mg) twice a day orally daily. The mean systolic (SBP) and diastolic blood pressure (DBP) on days 1 and 28 of the study were compared along with the mean arterial pressure (MAP).

Results: The mean SBP was significantly lesser on day $28(141.86 \pm 12.54 \mathrm{~mm}$ $\mathrm{Hg})$ as compared to the mean SBP recorded on day $1(155.48 \pm 19.37 \mathrm{~mm} \mathrm{Hg})$ $(\mathrm{p}<0.001)$. The mean DBP on day $28(89.66 \pm 6.8 \mathrm{~mm} \mathrm{Hg})$ was lesser than that on day $1(90.34 \pm 7.44 \mathrm{~mm} \mathrm{Hg})$ but this difference was not statistically significant $(\mathrm{p}>0.05)$. There was a significant decrease in the mean value of MAP on day 28 $(107.06 \pm 7.03 \mathrm{~mm} \mathrm{Hg})$ as compared to that on day $1(112.06 \pm 10.75 \mathrm{~mm} \mathrm{Hg})$ $(\mathrm{p}<0.01)$.

Conclusions: Capsule Artyl significantly decreased the BP in hypertensive patients, without any adverse effects. Controlled trials are needed to confirm the positive outcome of this promising herbal formulation in hypertensive patients.
\end{abstract}

Keywords: Capsule artyl, Essential hypertension, Systolic blood pressure

\section{INTRODUCTION}

Hypertension has become a crucial health issue to tackle worldwide not only due to its increasing prevalence but also because of the severe complications associated with it. About $10-15 \%$ of the rural and $25 \%$ of the urban population are estimated to be affected by hypertension in India. Also, Government of India has estimated that by 2020, 159.46/1000 Indians will be suffering from hypertension. ${ }^{1,2}$ Moreover, multiple complications associated with hypertension is a cause of high mortality due to the disease. According to the World Health Organization (WHO) data released in 2014, 26\% of the deaths in India are due to cardiovascular disease. Another striking data is that $29 \%$ of strokes, $21 \%$ of acute myocardial infarction and $16 \%$ of ischemic heart disease in India are all attributed to hypertension. ${ }^{3}$

The current management of hypertension involves lifestyle modifications along with pharmacotherapy. The pharmacological agents used for the treatment include angiotensin converting enzyme (ACE) inhibitors, angiotensin receptor blockers (ARBs), calcium channel blockers (CCBs), diuretics and alpha blockers. However, these agents are not enough to control the blood pressure of patients. It has been estimated that in more than twothird hypertensive patients on treatment, the blood 
pressure cannot be controlled with a single pharmacological agent and they require multiple drugs. ${ }^{4} \mathrm{~A}$ recent Indian study has revealed that the control rates of blood pressure in hypertensive cases are as low as $1 / 10^{\text {th }}$ in rural and $1 / 5^{\text {th }}$ in the urban population. ${ }^{5}$ Other pitfalls of the pharmacological agents for hypertension include the plethora of adverse effects as well as the high costs associated with their use. Hence, there is a strong need to search safe and cost-effective options for the management of hypertension in India.

Ayurveda, the Indian traditional discipline of medicine, has been used by various physicians to treat multiple types of disorders. However, many of the herbal extracts have not been investigated thoroughly for their possible beneficial effects in the treatment of hypertension. Two of such herbal drugs are Brahmi (Bacopa monnieri) and Shunthi (Zingiber officinale). In Ayurveda, Brahmi is considered to be a powerful Medhya (brain tonic) and has been widely studied for its nootropic effect. However, it has also shown promise as an anti-stress as well as an antioxidative agent. ${ }^{6}$ There have been very few studies which have tried to evaluate the effect of Brahmi as an antihypertensive agent. ${ }^{7,8}$ Shunthi, the processed dry ginger is a popular herb used extensively in the Indian subcontinent as a food additive. The beneficial effect of Shunthi in cardiovascular disease has been known for long. ${ }^{9}$ According to a systematic review published by the British Medical Journal, many animal studies have established the beneficial effect of Shunthi as a dietary supplement to conventional anti-hypertensive drugs. However, the same review has stated the need for more clinical studies to assess the possible effect of Shunthi in hypertensive patients. $^{10}$

Capsule Artyl is a polyherbal Ayurvedic oral formulation which is made from the aqueous extracts of Brahmi (Bacoside 30\%) and Shunthi (Gingerol 2.5\%). Considering the beneficial anti-hypertensive effect of both these extracts individually, this combination looks like a promising agent that can help physicians, as well as the patients, tackle the grave problem of uncontrolled hypertension. Hence, we planned to conduct an open label pilot study to assess the efficacy and the safety of this promising herbal combination in patients suffering from essential hypertension at various health care centers in Maharashtra, India.

\section{METHODS}

This study was a four-week, open label, single arm, multicentric, pilot study which was conducted to evaluate the effect of capsule Artyl on blood pressure in hypertensive patients.

There were 30 patients belonging to the age group of 30 years to 70 years having pre-diagnosed essential hypertension with systolic blood pressure (SBP) between $140-170 \mathrm{~mm} \mathrm{Hg}$ were included in this study. These subjects were attending the out-patient departments
(OPDs) at different Madhavbaug clinics located in various cities of Maharashtra, India. The subjects enrolled in the study had to be willing to follow the protocol strictly over the four weeks of study period. Patients who were suffering from cardiovascular co-morbidities (left ventricular hypertrophy, heart block, congestive heart failure or coronary artery disease) were excluded from the study. Patients having deranged liver function tests or renal function tests, pregnant women or women planning pregnancy in the next 6 months were also excluded from the study. If the subjects failed to adhere to the protocol or decided to drop out of the study themselves or developed some complication due to increase in SBP and diastolic blood pressure (DBP) which would have required urgent treatment, then they were to be withdrawn from the study.

The study was initiated in November 2017 and completed in February 2018. The patients were prescribed capsule Artyl 500mg, to be taken twice daily for a period of 28 days, along with the conventional treatment, if it was ongoing for the patient. All the patients were motivated to modify their lifestyle and dietary habits. The assessment of SBP and DBP was done with the help of a sphygmomanometer after enrolment of the subject in the study, which was considered the baseline or day 1 reading. The follow up reading of SBP and DBP was taken at day 7 , day 14, day 21 and day 28. The weight, height, BMI and the concomitant medication data was noted down on day 1 and again on day 28. The mean arterial pressure (MAP) was also calculated for all the patients on day 1 and day 28 using the formula: $2 / 3^{\text {rd }} \mathrm{DBP}+1 / 3^{\text {rd }} \mathrm{SBP}$.

Data were analyzed using MS excel and Graphpad Instat softwares. The data were represented as mean \pm SD. The variables on day 1 and day 28 were compared to each other using paired student's t test. $\mathrm{P}$ value of less than 0.05 was considered significant for all the variables.

Table 1: Constituents of capsule Artyl.

\begin{tabular}{|ll|}
\hline Composition of Cap. Artyl & Percentage (\%) \\
\hline Brahmi (Bacopa monnieri) & 62.5 \\
\hline Shunthi (Zingiber officinale) & 34 \\
\hline Excipient & 3.5 \\
\hline
\end{tabular}

\section{RESULTS}

A total of 90 hypertensive patients were screened for participation in the study. Out of these 90 patients, 30 were included in the study based on the selection criteria. 29 of the 30 enrolled patients completed the full study period and the data collected from these 29 patients were analyzed at the end of the study (Figure 1). The demographic details of the patients have been mentioned in Table 2 .

Many of the patients $(n=11)$ were found to have hypertension for the first time on their visit to the Madhavbaug Clinic OPDs. These 11 patients were started on Capsule Artyl with the advice of lifestyle and dietary modifications. The remaining 18 patients were on 
concomitant allopathic medications, the details of which have been mentioned in Figure 2.

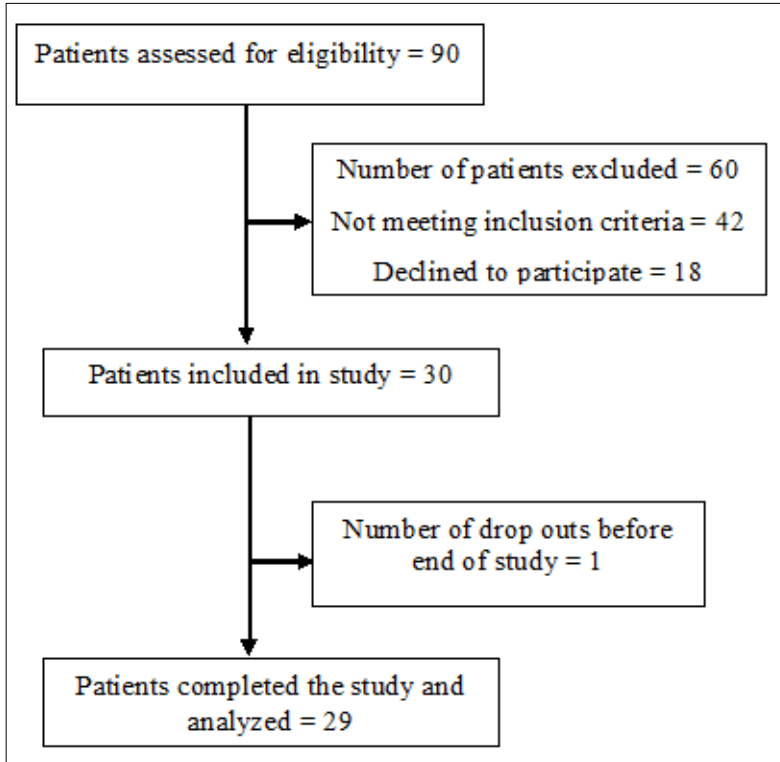

Figure 1: Patient enrolment flow chart.

Table 2: Demographic details of patients enrolled in the study $(n=29)$.

Mean demographic details of the study participants

Mean age of patients $=51.68 \pm 14.02$ years

Mean weight of patients $($ Day 1$)=70.29 \pm 10.65$

kilograms

Mean weight of patients (Day 28) $=70.12 \pm 10.80$

kilograms

Mean BMI of patients $($ Day 1$)=27.08 \pm 3.21 \mathrm{~kg} / \mathrm{m}^{2}$

Mean BMI of patients (Day 28) $=26.53 \pm 3.02 \mathrm{~kg} / \mathrm{m}^{2}$

Table 3: Effect of artyl treatment on improvement of Systolic Blood Pressure (SBP) from baseline to day 28 .

\begin{tabular}{|llllll|}
\hline SBP & $\begin{array}{l}\text { No. of } \\
\text { patients }\end{array}$ & Baseline & $\begin{array}{l}\text { Day } \\
\mathbf{2 8}\end{array}$ & Changes & $\begin{array}{l}\% \\
\text { changes }\end{array}$ \\
\hline 1. All & & & & & \\
\hline Mean & 29 & 155.48 & 141.86 & 13.62 & 8.76 \\
\hline $\begin{array}{l}\text { Standard } \\
\text { deviation }\end{array}$ & & 10.61 & 12.54 & & \\
\hline P value & $\mathrm{P}<0.001$ & & & & \\
\hline
\end{tabular}

Table 4: Effect of artyl treatment on improvement of Diastolic Blood Pressure (DBP) from baseline to day 28.

\begin{tabular}{|llllll|}
\hline DBP & $\begin{array}{l}\text { No. of } \\
\text { patients }\end{array}$ & Baseline & $\begin{array}{l}\text { Day } \\
\mathbf{2 8}\end{array}$ & Changes & $\begin{array}{l}\% \\
\text { changes }\end{array}$ \\
\hline 1. All & & & & & \\
\hline Mean & 29 & 90.34 & 89.66 & 0.69 & 0.76 \\
\hline $\begin{array}{l}\text { Standard } \\
\text { deviation }\end{array}$ & 6.68 & 6.80 & & \\
\hline P value & $\mathrm{P}>0.05$ & & & & \\
\hline
\end{tabular}

Table 5: Effect of Artyl treatment on improvement of Mean Arterial Pressure (MAP) from baseline to day 28.

\begin{tabular}{|llllll|}
\hline DBP & $\begin{array}{l}\text { No. of } \\
\text { patients }\end{array}$ & Baseline & $\begin{array}{l}\text { Day } \\
\mathbf{2 8}\end{array}$ & Changes & $\begin{array}{l}\text { \% } \\
\text { changes }\end{array}$ \\
\hline All & & & & & \\
\hline Mean & 29 & 112.06 & 107.06 & 5.00 & 4.46 \\
\hline $\begin{array}{l}\text { Standard } \\
\text { deviation }\end{array}$ & 6.29 & 7.03 & & \\
\hline P value & $P<0.01$ & & & & \\
\hline
\end{tabular}

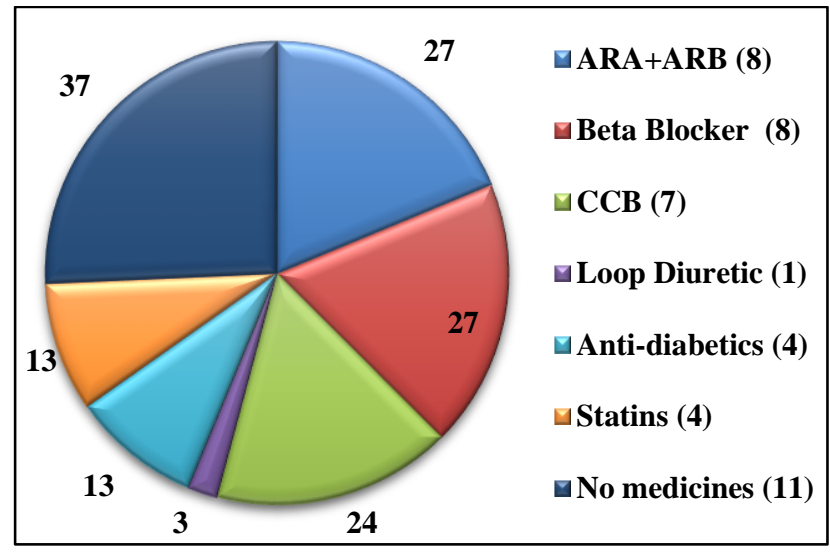

$\mathrm{ARA}=$ Antagonist receptor blocker, $\mathrm{ARB}=$ Angiotensin Receptor Blockers, $\mathrm{CCB}=$ Calcium Channel Blockers

Figure 2: Percentage of subjects using allopathy medicines $(n=29)$.

The mean SBP on day 28 was compared with that at baseline using Paired t-test; $\mathrm{P}<0.05$ considered significant (Table 3). The efficacy parameters were analyzed at baseline (day 1) and on the last day of the study (day 28). It was found that the mean SBP was significantly lesser on day $28(141.86 \pm 12.54 \mathrm{~mm} \mathrm{Hg})$ as compared to the mean baseline SBP of the patients recorded on day 1 $(155.48 \pm 19.37 \mathrm{~mm} \mathrm{Hg})(\mathrm{p}<0.001)$. The decrease in the mean SBP was by a margin of $8.76 \%$ (Figure 3 ).

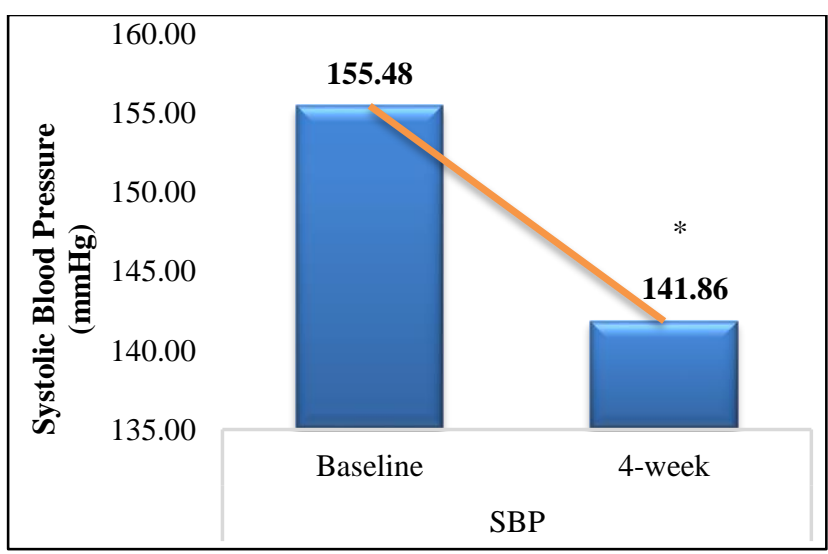

Comparison of the mean values done by paired t-test.

*: $p<0.05$ considered a statistically significant difference

Figure 3: Comparison of mean Systolic Blood Pressure (SBP) at baseline and at 4 weeks $(n=29)$. 
The mean DBP on day $28(89.66 \pm 6.8 \mathrm{~mm} \mathrm{Hg})$ was lesser than that on day $1(90.34 \pm 7.44 \mathrm{~mm} \mathrm{Hg})$ but this difference was not statistically significant $(p>0.05)$. The decrease in mean DBP was $0.76 \%$ (Figure 4 ).

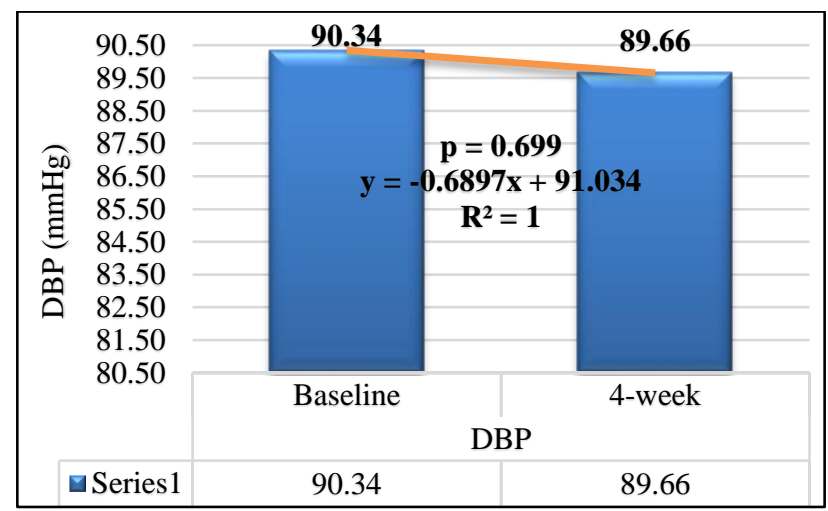

Comparison of the mean values done by paired t-test.

The mean values were not found to be statistically different from each other $(p>0.05)$

Figure 4: Comparison of mean Diastolic Blood Pressure at baseline and at 4 weeks $(n=29)$.

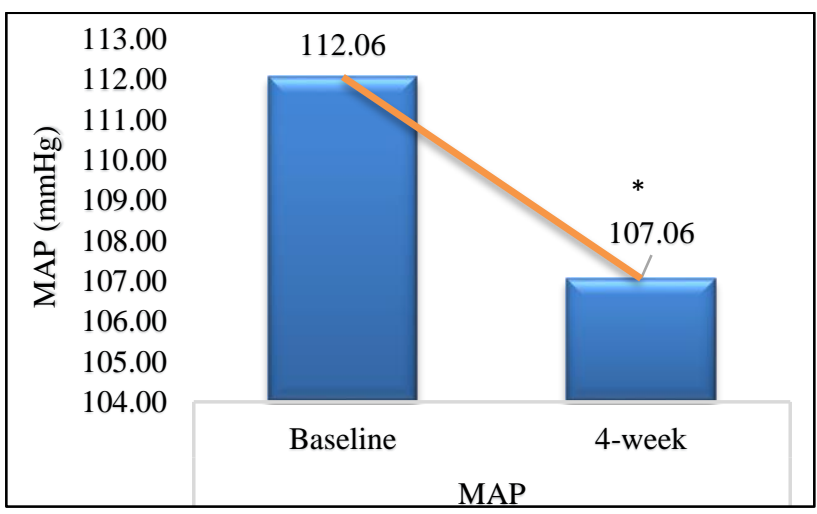

Comparison of the mean values done by paired t-test.

*: $\mathrm{p}<0.05$ considered a statistically significant difference

Figure 5: Comparison of mean values of mean arterial pressure at baseline and at 4 weeks $(n=29)$.

There was a significant decrease in the mean value of MAP on day $28(107.06 \pm 7.03 \mathrm{~mm} \mathrm{Hg})$ as compared to that on day $1(112.06 \pm 10.75 \mathrm{~mm} \mathrm{Hg})(\mathrm{p}<0.01)$. The difference in the mean values of MAP was $4.46 \%$ (Figure 5). None of the participants in the study developed any kind of adverse event over the study period.

\section{DISCUSSION}

Hypertension is one of the most common and dangerous non-communicable disease affecting the world population. The complications associated with the disease is a grave concern, especially because of the high rates of uncontrolled BP in the patients with hypertension, despite being on the standard pharmacological treatment. An Indian study published in 2014 concluded that the control rates of blood pressure in hypertensive cases on medication are just about $10 \%$ in rural and $20 \%$ in the urban population. ${ }^{5}$ Current drugs used for hypertension are not only associated with adverse effects but are also not cost-effective. ${ }^{11}$ Hence, it is important to look to alternative medicine for more efficacious, safe and costeffective options to treat hypertension. This search took us to Ayurveda, the Indian discipline of traditional medicine. Two herbal drugs, namely Brahmi (Bacopa monnieri) and Shunthi (Zingiber officinale) have been studied by researchers for their possible anti-hypertensive effect individually. However, none of them has studied a combination of these herbal medicines for the treatment of hypertension. Capsule Artyl is a herbal drug made by combining the extracts of Brahmi and Shunthi. Considering the surrounding evidence and the need for new medicines to control hypertension, we conducted this study.

On analyzing the collected data from the 29 participating hypertensive patients, we found that there was a statistically significant decrease in the mean SBP and the mean values of MAP on day 28 as compared to the baseline reading. The mean DBP was also found to be lower on day 28 as compared to the baseline reading, however this difference was not statistically significant. None of the patients on capsule Artyl showed any adverse effect in the study, and thus the formulation can be considered safe. These results were in sync with many of the studies conducted using Brahmi and Shunthi individually.

In a preclinical study conducted in Thailand, it was found that Brahmi reduces the blood pressure significantly in Wistar rats. ${ }^{7}$ In a clinical study conducted in India, Brahmi was found to decrease SBP, DBP and MAP significantly at 4 weeks of treatment, similar to the findings in this study. ${ }^{8}$

Shunthi, the processed dry ginger, has shown promising results individually in various studies as an antihypertensive agent. In a study conducted in China, daily consumption of ginger was associated with decreased risk of hypertension in adults (OR $=0.92, \mathrm{CI}$ : 0.87-0.99). ${ }^{12} \mathrm{~A}$ clinical study conducted in hypertensive patients of Egypt showed a statistically significant decrease in SBP and DBP at the end of 4 weeks of taking ginger with the prescribed medication. ${ }^{13}$ A systematic review on ginger published in the British Medical Journal concluded that animal studies have found ginger to have the potential to offer natural anti-hypertensive effect when taken as a supplement to conventional anti-hypertensive drugs. ${ }^{10}$

Preclinical studies have assessed the possible mechanism of actions behind the antihypertensive effects of Brahmi and Shunthi. The study conducted by Kamkaew et al. found that the fall in blood pressure caused by Brahmi is because of its vasodilatory effects on the resistance arteries. The researchers also found that this vasodilation is through the nitric oxide pathway. At high concentrations, Brahmi was found to decrease the contractions generated by the voltage gated calcium 
channels and reduce the action of calcium release from the sarcoplasmic reticulum. ${ }^{7}$ Brahmi has also shown antistress as well as anti-oxidant property, which may also play a role in its anti-hypertensive action. A pre-clinical study in Nigeria found that Shunthi (ginger) showed ACE inhibitory activity in vivo which could be the reason behind its BP lowering action. ${ }^{14}$ A study conducted by Ghayur et al found that ginger exhibited a vasodilator action through the blockage of the voltage gated calcium channels, which may be another possible mechanism behind its anti-hypertensive action. ${ }^{9}$

Our study had a few limitations. It was a one arm pilot study which was done mainly as a proof of concept research with low sample size and without a control arm. Sphygmomanometer was used to assess the SBP and the $\mathrm{DBP}$, which is a subjective tool to measure $\mathrm{BP}$ in comparison to ambulatory $\mathrm{BP}$ monitoring. The study duration was just 28 days, due to which long term efficacy and safety of capsule Artyl was not assessed.

\section{CONCLUSION}

Our preliminary study has found that capsule Artyl, which is a herbal drug produced by combining Brahmi and Shunthi, is successful in significantly decreasing the BP in hypertensive patients, without any adverse effects. Considering that this was a pilot one-arm study, controlled trials with larger sample size are needed to confirm the positive outcome of this promising herbal drug in hypertensive patients.

\section{ACKNOWLEDGEMENTS}

The authors thank the study participants and their families, without whom this study would not have been accomplished. Special thanks to the clinical research coordinators Snehal Patil, Reshma Thavai and Chandankumari Dubey for the management and completion of the study and Dr. Kritarth Naman Singh for medical writing.

Funding: Funding sources from Vaidya Sane Ayurvedic Education and Agricultural Research Trusts

Conflict of interest: None declared

Ethical approval: The study was approved by the Institutional Ethics Committee

\section{REFERENCES}

1. Tiwaskar M. Hypertension Control in India: Are we there Yet? OR Uncontrolled and Resistant Hypertension: The Indian Perspective. J Assoc Physicians India. 2016;64(7):11-2.

2. Indian Guidelines on Hypertension-III. J Clin Prev Cardiol. 2013;3:128-61.
3. Mohan S, Campbell N, Chockalingam A. Time to effectively address hypertension in India. Indian J Med Res. 2013;137:627-31.

4. Black HR, Elliott WJ, Grandits G, Grambsch P, Lucente T, White WB, et al. Principal results of the controlled onset verapamil investigation of cardiovascular end points (CONVINCE) trial. JAMA. 2003;289:2073-82.

5. Anchala R, Kannuri NK, Pant H, Khan H, Franco OH, Di Angelantonio E, et al. Hypertension in India: a systematic review and meta-analysis of prevalence, awareness, and control of hypertension. J Hypertens. 2014;32:1170-7.

6. Hussain GM, Mishra D, Singh PN, Rao ChV, Kumar V. Ethnopharmacological review of native traditional medicinal plants for brain disorders. Pharmacognosy review. 2007;1(1):19-29.

7. Kamkaew N, Scholfield C, Ingkaninan K, Maneesai P, Parkington H, Tare M, et al. Bacopa monnieri and its constituents is hypotensive in anaesthetized rats and vasodilator in various artery types. $\mathrm{J}$ of Ethnopharm. 2011;137(1):790-5.

8. Mishra D, Tubaki B. The effect of Brahmi vati and Sarpagandha Ghana vati in management of essential hypertension - A randomized, double blind, controlled clinical study. Journal of Ayurveda and Integrative Medicine; 2017.

9. Ghayur M, Gilani A. Ginger Lowers Blood Pressure Through Blockade of Voltage-Dependent Calcium Channels. J of Cardio Pharmac. 2005;45(1):74-80.

10. Torabi M, Naeemzadeh F, Ebrahimi V, TaleschianTabrizi N, Pashazadeh F, Nazemie H. The Effect of Zingiber Officinale (Ginger) On Hypertension; A Systematic Review of Randomised Controlled Trials. BMJ Open. 2017;7(0):A1-A78.

11. Kapoor A, Kumar A, Mahapatra AK, Chauhan G. Open clinical trial of a polyherbal compound $\mathrm{M}$ Sarpagandhamishran in essential hypertension: a pilot study. Int J Res Ayurveda Pharm. 2014;5(5):594-9.

12. Wang Y, Yu H, Zhang X, Feng Q, Guo X, Li S, et al. Evaluation of daily ginger consumption for the prevention of chronic diseases in adults: a crosssection study. Nutrition; 2016.

13. Shaban MI, El-Gahsh NFA, El-Said A, El-Sol H. Ginger: It's Effect on Blood Pressure among Hypertensive Patients. IOSR Journal of Nursing and Health Science. 2017;6(5):79-86.

14. Akinyemi A, Ademiluyi A, Oboh G. Inhibition of Angiotensin-1-Converting Enzyme Activity by Two Varieties of Ginger (Zingiber officinale) in Rats Fed a High Cholesterol Diet. Journal of Medicinal Food. 2014;17(3):317-23.

Cite this article as: Sane R, Dawkhar S, Ambulkar $\mathrm{P}$, Mandole R. The effect of a polyherbal oral formulation in the management of essential hypertension: an open label, pilot clinical study. Int J Basic Clin Pharmacol 2018;7:1427-31. 